\title{
The Microstructure and Martensitic Transformation in Ni-Al Alloys with Yttrium Addition
}

\author{
T. Czeppe, Y.N. Koval* and G.E. Monastyrsky* \\ Aleksander Krupkowski Institute of Metallurgy and Materials Science, Polish Academy of Sciences, \\ 25 Reymonta St., 30-059 Kraków, Poland \\ * Institute of Metal Physics, Ukrainian Academy of Sciences, 36 Vernadsky blvd., 252680 Kiev, Ukraine
}

\begin{abstract}
The microstructure and martensitic transformation in the Ni-36.3Al-0.4Y (in at.\%) alloy were investigated after homogenisation and plastic deformation by hot upsetting at $1100^{\circ} \mathrm{C}$. The alloy exhibited large, recrystallised grains of the $\mathrm{Ni}-\mathrm{Al} \beta$ phase with spherical precipitates inside the grains and a thin layer of other phases located at the grain boundaries. The SEM and EDX analysis showed that both types of precipitates were composed of two intermetallic phases $\left(\mathrm{Ni}_{\mathrm{x}} \mathrm{Al}_{1-\mathrm{x}}\right) \mathrm{Y}_{5}$ with different $\mathrm{Ni}$ to $\mathrm{Al}$ ratio. No yttrium content has been detected in the matrix $\beta$ phase, probably because of the low solubility limit which is 0.1 at.\%. The martensitic transformation was studied by TEM and DSC calorimetry. In large grains of the recrystallised material the $M_{s}$ temperature was measured to be $-4^{\circ} \mathrm{C}$ and the transformation proceeded in the range of 60 deg. The $\mathrm{M}_{s}$ temperature was lower than expected from the ratio of $\mathrm{Ni}$ to $\mathrm{Al}$. Aging 1 hour at $240^{\circ} \mathrm{C}$ did not influence the range of the transformation. The TEM study of the $\beta$ phase revealed strong and regular contrast modulations, probably being premartensitic effects. Also a regular spaced network of dislocations lying in the same directions as the contrast modulations, both in matrix and martensite, was noticed. In foils $7 \mathrm{R}$ structure of martensite, internally twinned, was predominantly found. The alloy was very brittle.
\end{abstract}

\section{INTRODUCTION}

The nonstoichiometric intermetallic NiAl compound is thought to be promising as a future constructive material for high temperature application [1]. In the range of temperature which strongly depends on $\mathrm{Ni}$ content, the $\beta$ phase undergoes the thermoelastic martensitic transformation [2]. This makes the alloy potentially suitable as a shape memory material [1]. However, at the chemical composition far from stoichiometry, at temperature lower than $600 \mathrm{~K}$, NiAl exhibits lack of plasticity and very high brittleness which, together with the observed transformation of martensite to $\mathrm{Ni}_{5} \mathrm{Al}_{3}$ phase during prolonged aging, makes the application of this alloy, either as constructive or shape memory material, rather problematic. Many attempts to increase the poor ductility of $\mathrm{NiAl}$ were undertaken by micro- and macro- alloying $[3,4]$. The problem seems to be not solved yet. The present paper is aimed at the study of the influence of 0.4 at. \% yttrium addition on the matrix phase structure and thermoelastic martensitic transformation in the $\mathrm{Ni}-\mathrm{Al}$ alloy. Yttrium, exhibiting large effective atomic radius in comparison with $\mathrm{Ni}$ and $\mathrm{Al}$ atoms and small $\left(0.1\right.$ at. $\%$ at $1250^{\circ} \mathrm{C}$ [5]) solubility in $\mathrm{Ni}$, may influence properties of perfectly ordered $\mathrm{NiAl} \beta$ phase [6].

\section{EXPERIMENTAL PROCEDURE}

The investigated alloy was prepared by arc melting from high purity components. After casting the alloy revealed strong dendritic composition inhomogenity. The chemical composition of the alloy was determined to be: Ni-36.3Al-0.4Y (in at.\%). The homogenization in the $\beta$ phase temperature range was performed in a quartz ampoule under a protective argon atmosphere. The first homogenization was performed at temperature $1200^{\circ} \mathrm{C}$. The sample was homogenous but extreme brittleness made preparing material for the TEM investigations very difficult. Because of that a successful attempt of the high 
temperature plastic deformation by hot upsetting was performed [7]. The sample was upset in the "soft" steel matrix, at the $1100^{\circ} \mathrm{C}$ after prolonged annealing at that temperature. Such prepared material was much less brittle. Further investigations were performed on samples plastically deformed or after subsequent additional homogenization at $1370^{\circ} \mathrm{C}$. The microstructure and chemical composition of the alloy after casting, plastic deformation and homogenization, were studied with scanning electron microscope Philips XL30 and EDS. Martensitic transformation temperatures were measured using Du Pont 910 DSC microcalorimeter at cooling/heating rate of $20 \mathrm{~K} / \mathrm{min}$. The structure was investigated using Philips CM20 transmission electron microscope. In-situ studies were performed by means of Philips EM301 transmission electron microscope with cooling/heating stage. Thin foils were obtained at temperature $-30^{\circ} \mathrm{C}$, using jet electropolishing in $20 \%$ perchloric acid in methanol.

\section{RESULTS AND DISCUSSION}

\subsection{The microstructure of the alloy}

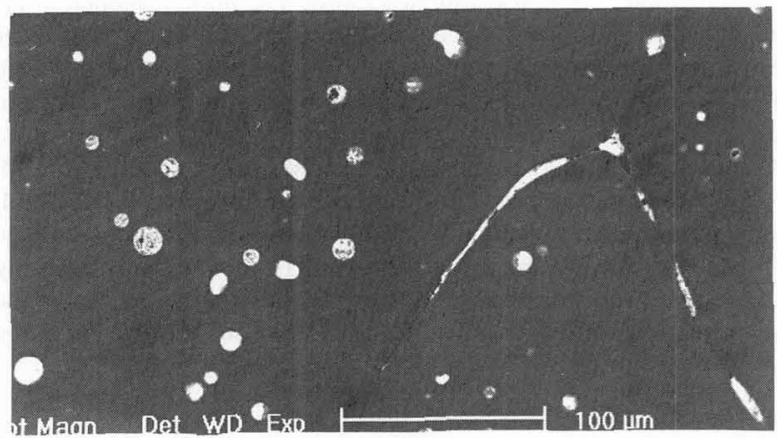

Fig. 1 Microstructure of the alloy after hot deformation at $1100^{\circ} \mathrm{C}$. seivi micrograph, magnification $250 x$.
The microstructure of the alloy after homogenization at $1200^{\circ} \mathrm{C}$ and after hot upsetting at $1100^{\circ} \mathrm{C}$ was very similar, except that smaller grains were observed in sample after plastic deformation. Optical and electron scanning microscopy revealed thin film of a phase at the grain boundaries and spherical precipitates in grains (Fig.1). In the case of the sample after hot deformation, smaller amount of the phase at the grain boundaries was formed than in the sample homogenized. Some parts of the $\beta$ phase boundaries were free from it.

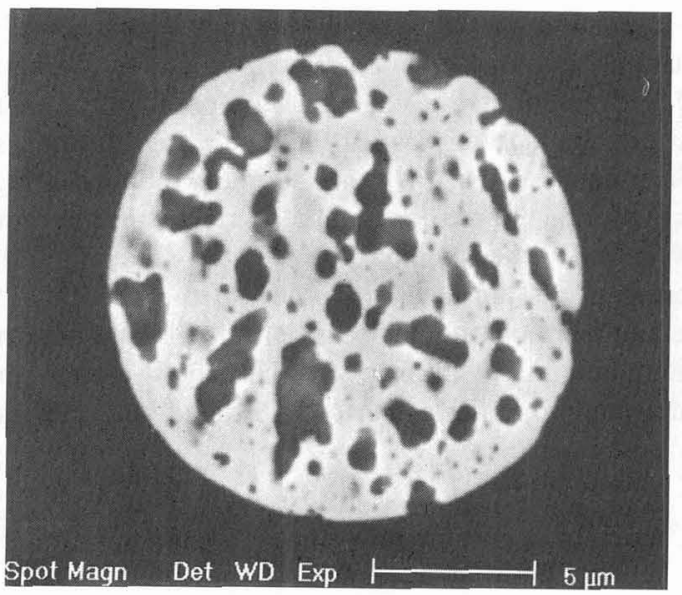

a)

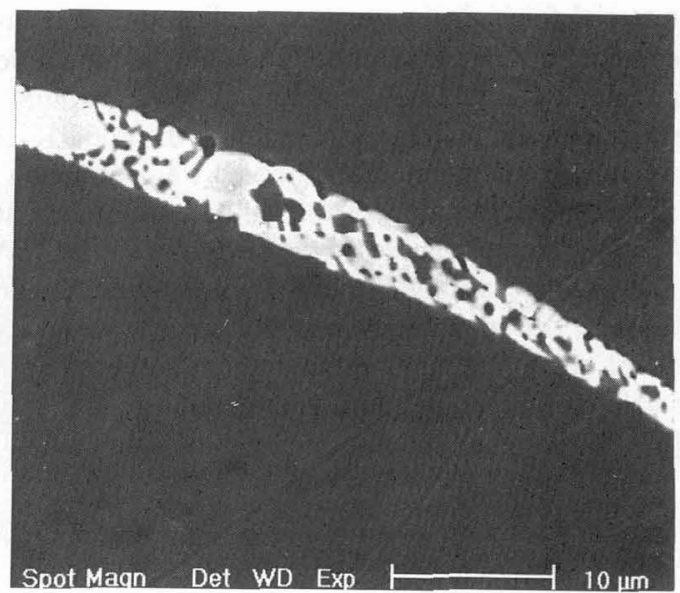

b)

Fig. 2 Precipitates in the alloy homogenized and hot deformed at $1100^{\circ} \mathrm{C}$. SEM microstructure; a) precipitates inside the grain, magnification $4000 \mathrm{x}$, b) precipitates at the grain boundaries, magnification $2000 \mathrm{x}$. Light and dark arcas inside the precipitates - intermetallic phase exhibiting high yttrium content. 


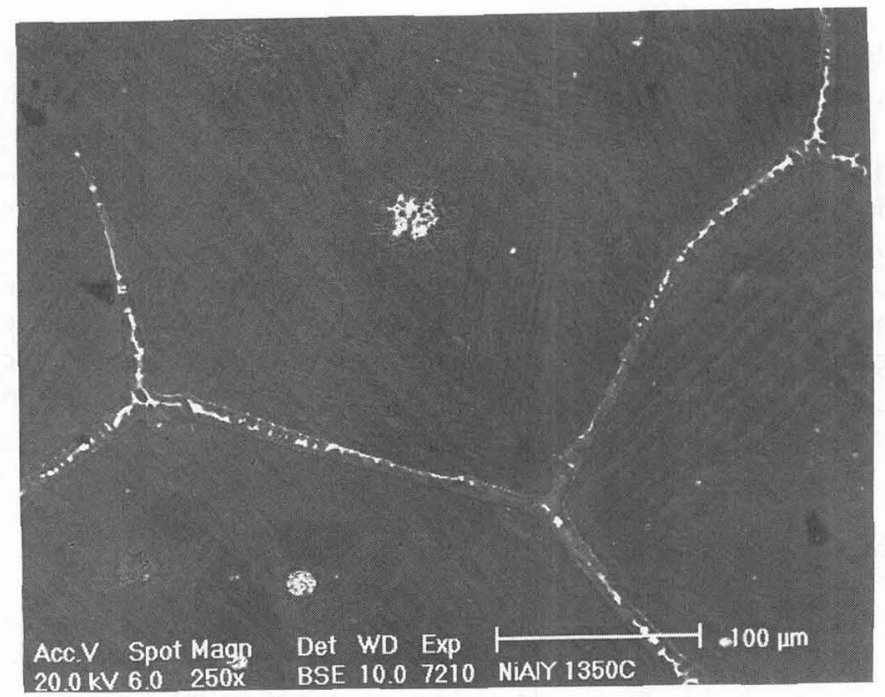

Fig. 3 Microstncture of the alloy after homogenization at $1370^{\circ} \mathrm{C}$. SEM micrograph, magnification $250 \mathrm{x}$.
This may explain comparatively smaller brittleness of that sample. EDS analysis of the matrix phase composition revealed no, yttrium content in it, giving as a result chemical composition: $\mathrm{Ni}-36.4$ at. $\%$ Al. Closer examination of the precipitates showed that both spherical ones and those at the grain boundaries are composed of two different phases. In the micrographs presented in Fig. 2 light areas revealed composition Ni-12.3Al-16.4Y and dark areas $\mathrm{Ni}-23.8 \mathrm{Al}-15.2 \mathrm{Y}$ (in at.\%). In both cases the composition agrees well with the intermetallic compound $\left(\mathrm{Ni}_{x} \mathrm{Al}_{1-x}\right)_{5} \mathrm{Y}$ existing in the ternary equilibrium diagram [8], but with different $\mathrm{Ni} /$ Al proportion: $\left(\mathrm{Ni}_{0.72} \mathrm{Al}_{0.28}\right)_{5} \mathrm{Y}$ in dark areas and $\left(\mathrm{Ni}_{0.85} \mathrm{Al}_{0.15}\right)_{5} \mathrm{Y}$ in light areas, first of them related to the $\mathrm{Ni}_{2} \mathrm{Al}$ composition.

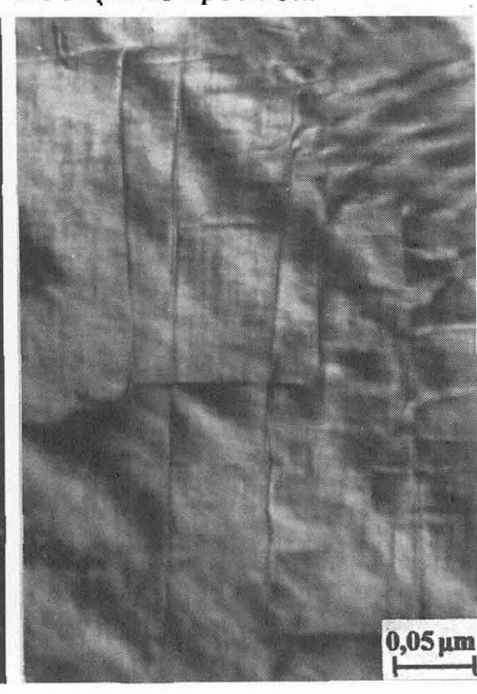

c

Fig. 4 The transmission electron microstructure of the $\beta$ phase after plastic deformation of the sample at $1100^{\circ} \mathrm{C}$; a) dislocation in the B2 structure, $88000 \mathrm{x}$; b) SADP of the B2 structure, strong (110) spots sidebands, foil orientation [010]; c) dislocations network, $115000 \mathrm{x}$, foil orientation [010].

The microstructure of the alloy after subsequent homogenization at $1370^{\circ} \mathrm{C}$ is presented in Fig. 3 . As it is shown two phases are still present but at the round - shape precipitates as well as at the grain boundaries of the "light" phase is surrounded by the "dark" one. The chemical composition of the phases determined by EDS was: Ni-8.1 Al-15.5Y (light phase) and Ni-27.0Al (dark phase) at the grain boundaries; $\mathrm{Ni}-5.4 \mathrm{Al}-14.4 \mathrm{Y}$ (light precipitates) and Ni-25.0Al-0.1Y (dark precipitates). The light phase composition 
may be written as $\left(\mathrm{Ni}_{0.9} \mathrm{Al}_{0.1}\right)_{5} \mathrm{Y}$ while the dark precipitates have composition of $\mathrm{Ni}_{3} \mathrm{Al}$ phase with the same $\mathrm{Y}$ content as in the $\beta$ matrix, in which after homogenization at $1370^{\circ} \mathrm{C}$ also about 0.1 at. $\%$ of $\mathrm{Y}$ was detected.

Transmission electron microscopy study was performed on the sample after hot plastic deformation. The microstructure of the $\beta$ phase is presented in Fig.4. The grains of the $\beta$ phase (B2 structure) contain high density of dislocations. As one may see in Fig.4a dislocations are directed along the traces of the perpendicular planes of $\{110\}$ type. This type of dislocation, as is seen when the foil is symmetrically oriented in [010] or [011] direction, forms the dislocation network (Fig. 4c). On the traces of the planes of type $\{100\}$ the other type of dislocation, which connect two dislocations on $\{110\}$ planes, also typical for the bcc structure may be seen in the Fig.4a. In the diffraction pattern (Fig. 4b) sidebands of the fundamental and superlattice spots in $\langle 100\rangle$ directions and streaks in $\langle 110\rangle$ directions are visible. These effects have premartensitic character and are related to the fine contrast modulation in $\langle 011\rangle$ directions in the microstructure [9]. In situ heating up to $500^{\circ} \mathrm{C}$ lead to the vanishing of the dislocations but had no influence on the fine modulations, supporting their interpretation as premartensitic effects.

\subsection{Martensitic transformation and the structure of martensite}

In Fig, 5 thermal curves of the hot deformed sample are shown. The $M_{s}$ temperature was detected to be $-4^{\circ} \mathrm{C}$. Temperature $\mathrm{M}_{s}$ lower than may be expected from $\mathrm{Ni} / \mathrm{Al}$ proportion [10] results most probably from high concentration of structural defect (high density of dislocations). However an influence of a small amount of $Y$ dissolved in the lattice, below the sensitivity of EDS method also may not be excluded. The transformation temperature range was rather wide, $A_{f}-M_{f}$ was about $60 \mathrm{deg}$. Aging 1 hour in $240^{\circ} \mathrm{C}$ influenced neither the thermal effects nor the transformation temperatures.

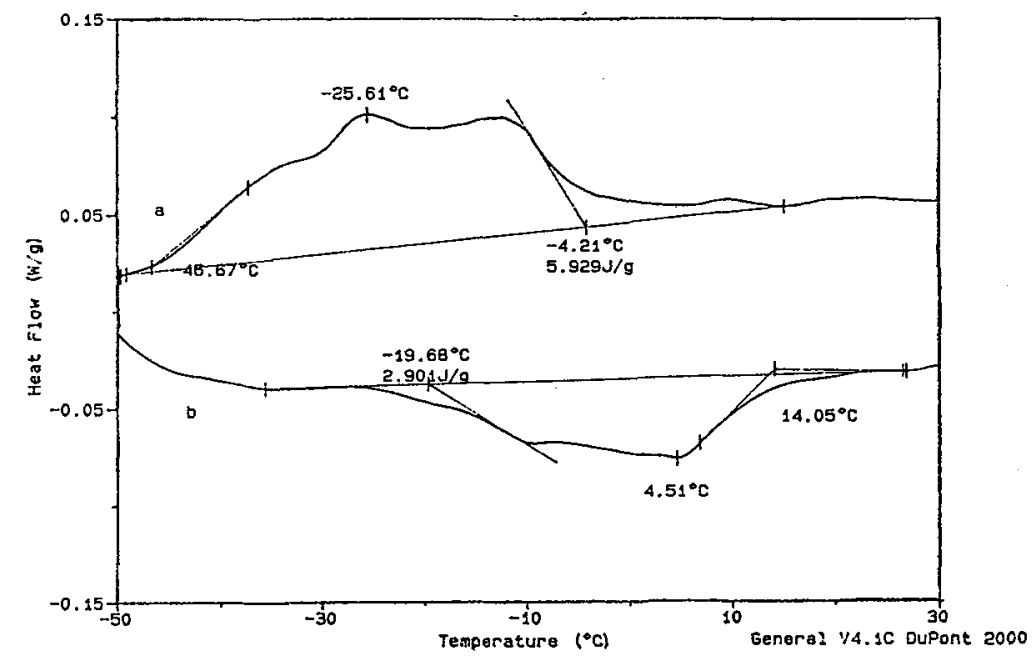

Fig. 5 Martensitic transformation in the sample after hot deformation; DSC curves: $\mathbf{a}$ - cooling, $\mathbf{b}$ heating, speed $20 \mathrm{~K} / \mathrm{min}$.

The structure of the martensite observed in the sample was predominately 7R ordered [11]. In Fig. 6 and 7 the microstructure of martensite formed in in-situ experiment is shown. In the BF micrographs different orientations of microtwins are visible. In the DF the dislocation network, accommodated during the transformation is shown. In some cases martensite of $3 \mathrm{R}$ structure was also noticed. The orientation relationships between $7 \mathrm{R}$ martensite and $\beta$ matrix are shown at the SADP in Fig.8. The [001] and [100] directions of the $7 R$ structure are inclined about $2^{\circ}$ to the two perpendicular directions of the $<110>$ type 
in the bcc structure. Pairs of the $\langle 110\rangle_{\text {boc }}$ spots sidebands coincide in the diffraction pattern with the spots belonging to the $(10 \mathrm{~L})$ row of the $7 \mathrm{R}$ structure, what indicates their relation to the premartensitic structures [12].

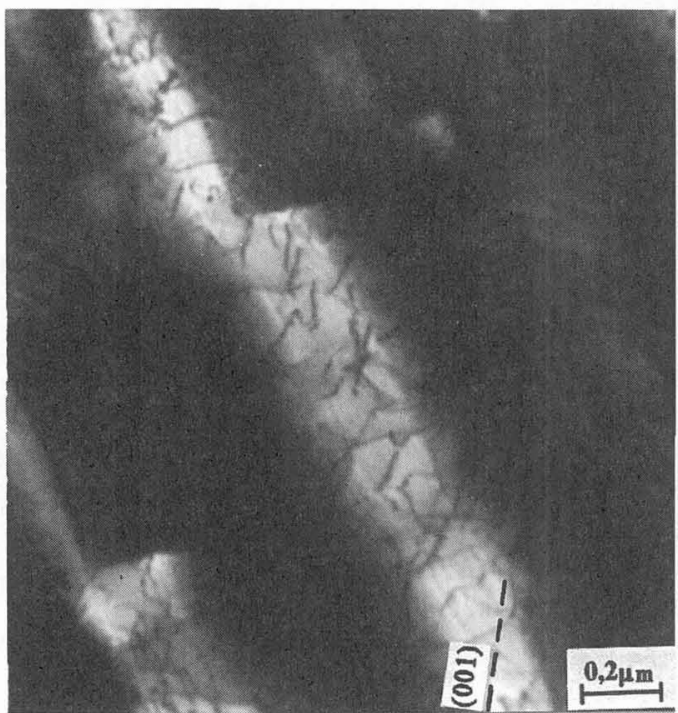

a

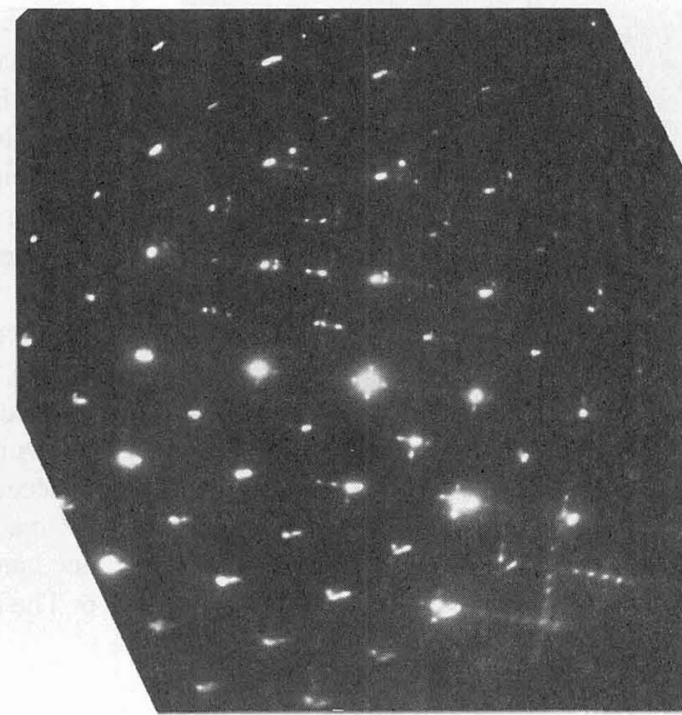

b

Fig. 6 The microstructure of martensite, cooling in-situ, temp. $-160^{\circ} \mathrm{C}$; a) $\mathrm{BF}$, magnification $28000 \mathrm{x}$ b) $\mathrm{SADP}$ of $7 \mathrm{R}$ martensite structure; foil orientation $[010]_{7 \mathrm{R}}$.

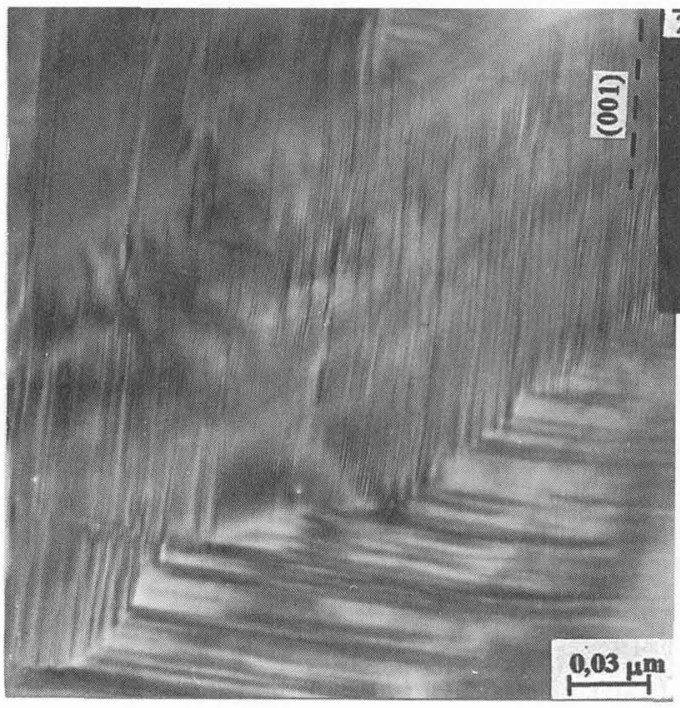

\section{$\overline{2} 07$}

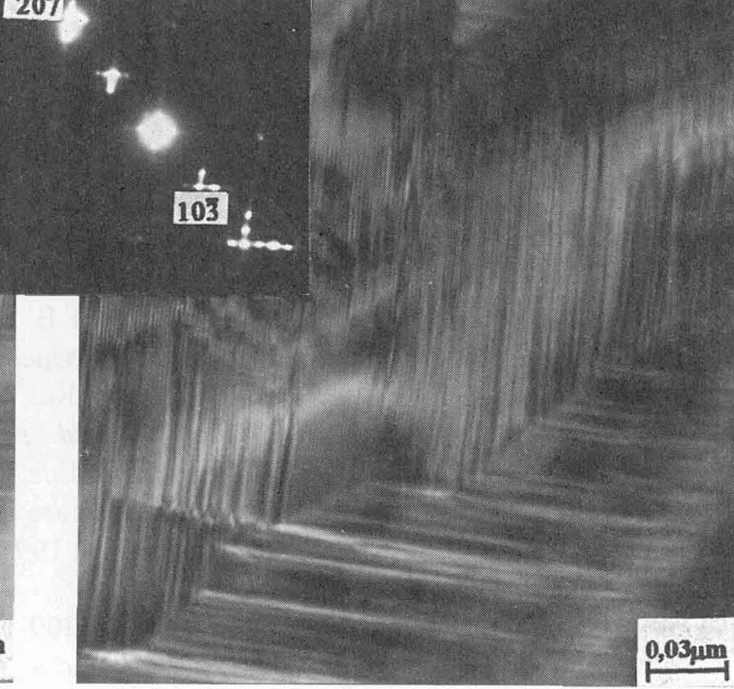

c

Fig. 7:The microstructure of martensite, R.T.; a) BF, magnification $200000 \mathrm{x}$ b) SADP of 7R martensite structure; foil orientation $\left.[010]_{7 \mathfrak{R}}, \mathrm{c}\right)$ DF from (103) spot, magnification $200000 \mathrm{x}$. 


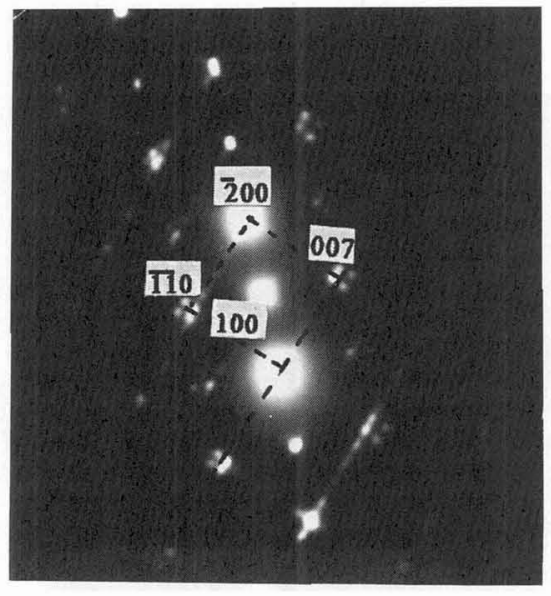

Fig. 8 SADP from the martensite $7 \mathrm{R}$ and $\mathrm{B} 2$ matrix structures showing typical orientation relationship between the structures; foil orientation $[010]_{\mathrm{R}} / /[001]_{\mathrm{B} 2}$.

\section{CONCLUSIONS}

1.After homogenisation at $1370^{\circ} \mathrm{C}$ precipitates of $\left(\mathrm{Ni}_{x} \mathrm{Al}_{1-x}\right)_{5} \mathrm{Y}$ and of $\mathrm{Ni}_{3} \mathrm{Al}$ phases were formed at the boundaries and in the grains of $\beta$ matrix.

2. In the sample homogenised at $1100^{\circ} \mathrm{C}$ and hot deformed two $\left(\mathrm{Ni}_{\mathrm{x}} \mathrm{Al}_{1-\mathrm{x}}\right)_{5} \mathrm{Y}$ phases with different $\mathrm{Ni} / \mathrm{Al}$ proportions precipitated.

3. The microstructure of the $\beta$ phase after hot deformation revealed high density of dislocations on the $\{110\}$ planes which formed dislocation network. The dislocations on $\{100\}$ planes were also formed.

4. In the $\beta$ phase strong premartensitic effects were noticed.

5. During cooling reversible martensitic transformation proceeded with $\mathrm{M}_{s}$ temperature $-4^{\circ} \mathrm{C}$. Predominantly the $7 \mathrm{R}$ martensite structure was formed. The dislocations were accommodated in the martensite structure.

6. The alloy with yttrium addition remained very brittle.

\section{Acknowledgments}

The authors wish to thank dr S. Szczepanik from Academy of Mining and Metallurgy in Kraków for performing the hot upsetting of the alloy.

This research was supported by the Polish State Committee for Scientific Research under grant No 3P 40706306.

\section{References}

[1] Miracle D.B., Acta Metall. Mater.,41 (1993) 649-684

[2] Chakravorty S., Wayman C.M., Metall. Trans.,7A (1976) 555-569

[3] Ishida K., Kainuma R., Ueno N., Nishizawa T., Metall. Trans.,22A (1991) 441-446

[4] George E.P., Liu C.T., J. Mater. Res., 5 (1990) 754

[5] Binary Alloy Phase Diagrams vol.3, Massalski T.B. Ed, (ASM Int. 1990) p.2884

[6] Vehoff H., "Fracture and Toughness of Intermetallics", High -Temperature Ordered Intermetallic AlloysV, Boston USA 30 Nov.-3 Dec.1992, (Mat. Res. Soc. Symp. Proc. vol.288), pp.71-82

[7] Czeppe T., S.Szczepanik S., Journal of Material Processing Technology, 60 (1996) 317

[8] Ternary Alloys vol.8, Petzow G., Effenberg G. Eds, (ASM Int.1993) p.58

[9] Zheng-Y., Stobbs W., "The tweed Microstructure in B2 Ni-rich Ni-Al Alloys", Electron Microscopy and Analysis Group Conf. EMAG 95, Birmingham 1995, (Inst.Phys.Conf.Ser. No147; Section 9) pp.353-356

[10] Au Y.K., Wayman C.M., Scr. Met. 6 (1972) 1209-1214

[11] Murakami Y., Otsuka K., Hanada S., Watanabe S., Materials Transactions JIM 33 (1992) 282-288

[12] Tanner L.E., Schryvers D., Shapiro S.M., Materials Science Eng. A127 (1990) 205-213 